\title{
Agroecological assessment of water-physical properties of irrigated soils of the Trans-Urals in the analysis of the main hydrophysical characteristics
}

\author{
I.V. Komissarova*, A.V. Chelovechkova, and N.V. Miroshnichenko \\ Kurgan State Agricultural Academy named after T.S. Maltsev, Kurgan, Russia
}

\begin{abstract}
Water-physical properties of soils are a set of soil properties that determine the accumulation, preservation and water transfer in the soil stratum. One of the important indicators of water-physical properties are soil-hydrological constants. These indicators can be used in forecasting yield, calculating the irrigation rate. The determination of soil-hydrological constants is a rather laborious process. In this article, we propose to obtain soil-hydrological constants from the data of the main hydrophysical characteristics. This technique allows to analyze the data and obtain soil-hydrological constants from the data of granulometric composition. The conducted studies have shown that the use of uncontrolled irrigation has led to the transformation of waterphysical properties, the content of easily mobile, productive and gravitational moisture has decreased. When modeling the MHC curve, a change in the shape on the graphs can be noted.
\end{abstract}

\section{Introduction}

The conditions of active exploitation of the land fund are one of the problems of modern agriculture. As a result, the quality of the soil decreases, the capabilities of agroecosystems are damaged, which leads to a decrease in crop productivity. At present time, irrigation agriculture is a very promising direction when working with land funds. Nevertheless, practice shows that without justification of irrigation methods and norms, without considering the characteristics of the soil, irrigation can lead to degradation of the soil cover. Soil processes occurring on irrigated and non-irrigated soils depend on the type and method of use. As a rule, continued irrigation leads to a change in the granulometric composition. In particular, there is a destruction of larger fractions and their transition to smaller fractions. As a result, there is an increase in the content of fractions of physical clay, silt and fine dust and a decrease in the fraction of fine sand and coarse dust. The accumulation of the silty fraction affects the formation of the plough sole [1-4].

\footnotetext{
* Corresponding author: ir.komissarova@mail.ru
} 
To eliminate the causes that arise during irrigation development, both theoretical and experimental justification of methods for the development of agro-reclamation measures is necessary.

The purpose of the study was to conduct an agroecological assessment of the waterphysical properties of irrigated soils using the main hydrophysical characteristic (MHC). This characteristic occupies a central place in providing mathematical models for soil experiments. It should be noted that there are still no general standards for obtaining MHC. There are many methods that allow to determine individual sections of the water retention curve and restore the entire curve. In our work, we propose a method of program modeling of the MHC using the concept of A.D. Voronin. According to it, each soil-hydrological constant on the curve of the main hydrophysical characteristic corresponds to the moisture pressure. In addition, the soil-hydrological constants are related to the granulometric composition by regression equations [5,6]. Since pedotransfer functions allow the conversion of some indicators into others, they are widely used to calculate the values of soil parameters. To work with such functions, a database is needed containing the main traditional characteristics of soils.

\section{Materials and methods}

The research was carried out on the territory of the Kurgan vegetable variety testing site using archival materials of the Department of Agrochemistry and Soil Science of the Kurgan State Agricultural Academy on leached chernozem. The research area belongs to the central agro-climatic region. The studied site is located within the erosion-denudation landscape of the Trans-Ural forest-steppe subdistrict on the erosion terrace of the indigenous bank of the Tobol River. The soil-forming rocks are deluvial silty sandy loams that overlap the eroded surface of Paleogene clays, which caused the sandy loam composition of the soils. A specific feature of these deposits is a rather high proportion of sandy loam rocks with a silty fraction content, which explains the unfavorable physical properties of the isolated soils [7-9].

The object of the study was leached chernozems located in areas with different steepness $\left(<1^{0}, 3-5^{0}\right)$. Field work was carried out in the summer of 2020, where morphological features of the structure of the soil profile were studied. During the field work, the main sections were laid on the most typical terrain positions. The selection of soil samples was carried out from the section in layers with an interval of $0-10 \mathrm{~cm}$ at the same points as in 1986. The granulometric composition, the density of the solid phase, the density of the soil were determined in the laboratory and the total porosity was calculated. Based on the results of the conducted analyses, using the software method developed by the authors, a graph of the main hydrophysical characteristics (MHC) of the studied area is constructed. According to the graph, the soil-hydrological constants of the studied area are determined.

\section{Results and discussions}

Figures 1-4 show the graphs obtained as a result of the construction of the main hydrophysical characteristics, as well as the results of calculations of the soilhydrological constants of the leached chernozem of the studied area for 1986 and 2020. 


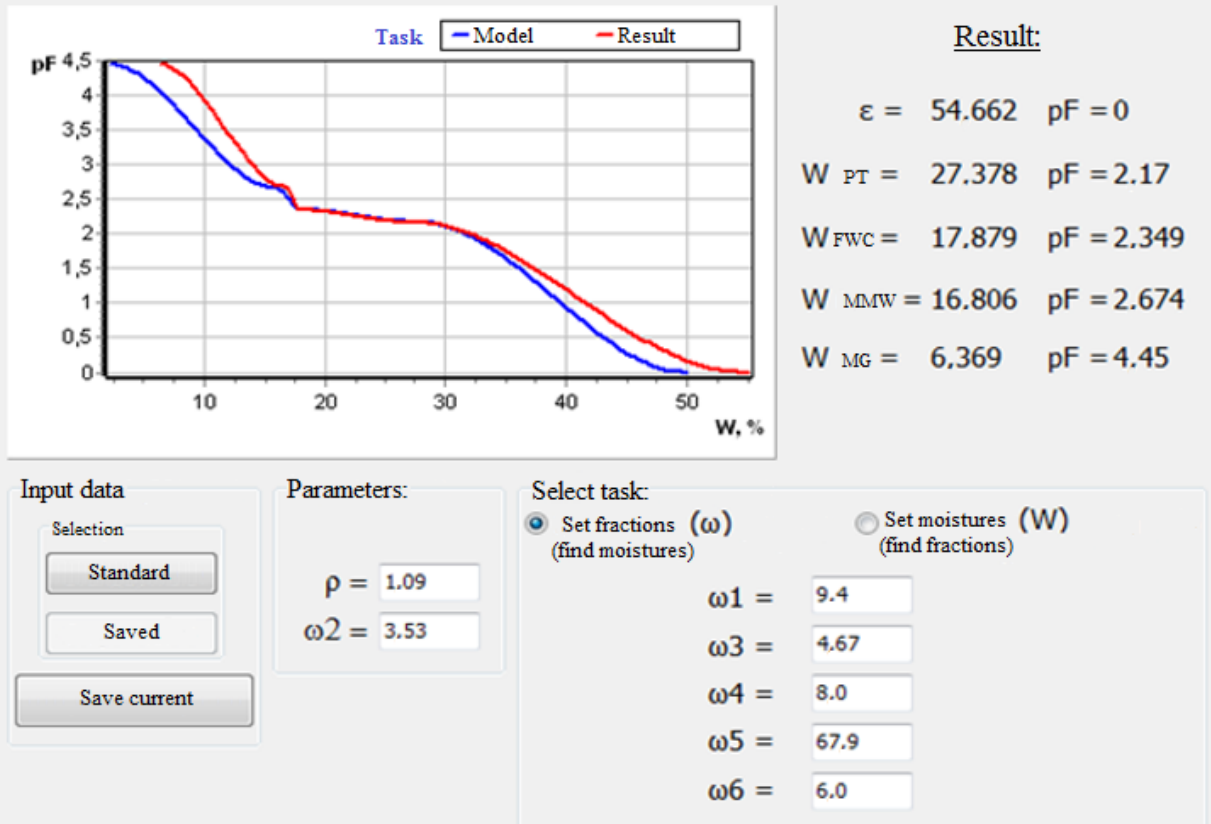

Fig. 1. Main hydrophysical characteristics 2020 section 1.

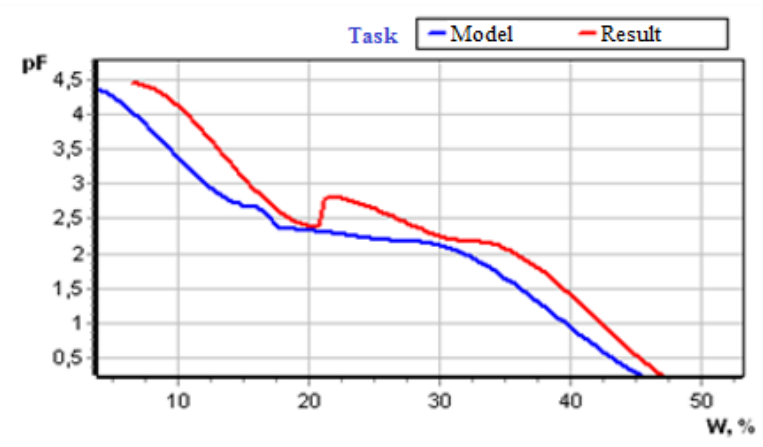

\section{$\underline{\text { Result: }}$}

$$
\varepsilon=50.945 \mathrm{pF}=0
$$

$\mathrm{W}_{\mathrm{PT}}=32.646 \mathrm{pF}=2.17$

$\mathrm{W}_{\mathrm{FWC}}=20.652 \mathrm{pF}=2.377$

$\mathrm{W}$ MMW $=21.301 \quad \mathrm{pF}=2.809$

$W_{M G}=6.456 \quad \mathrm{pF}=4.45$

\section{Input data}

Selection

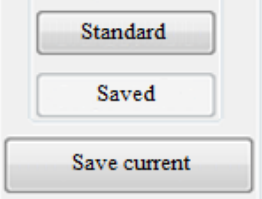

\section{Parameters:}

$$
\begin{aligned}
\rho & =1.24 \\
\omega 2 & =8.82
\end{aligned}
$$

\section{Select task: \\ - Set fractions $(\omega)$ (find moistures)}

Set moistures (W)

(find fractions)

$$
\begin{aligned}
& \omega 1=14,30 \\
& \omega 3=3.76 \\
& \omega 4=5.30 \\
& \omega 5=61.96 \\
& \omega 6=5,86
\end{aligned}
$$

Fig. 2. Main hydrophysical characteristics 2020 section 1. 

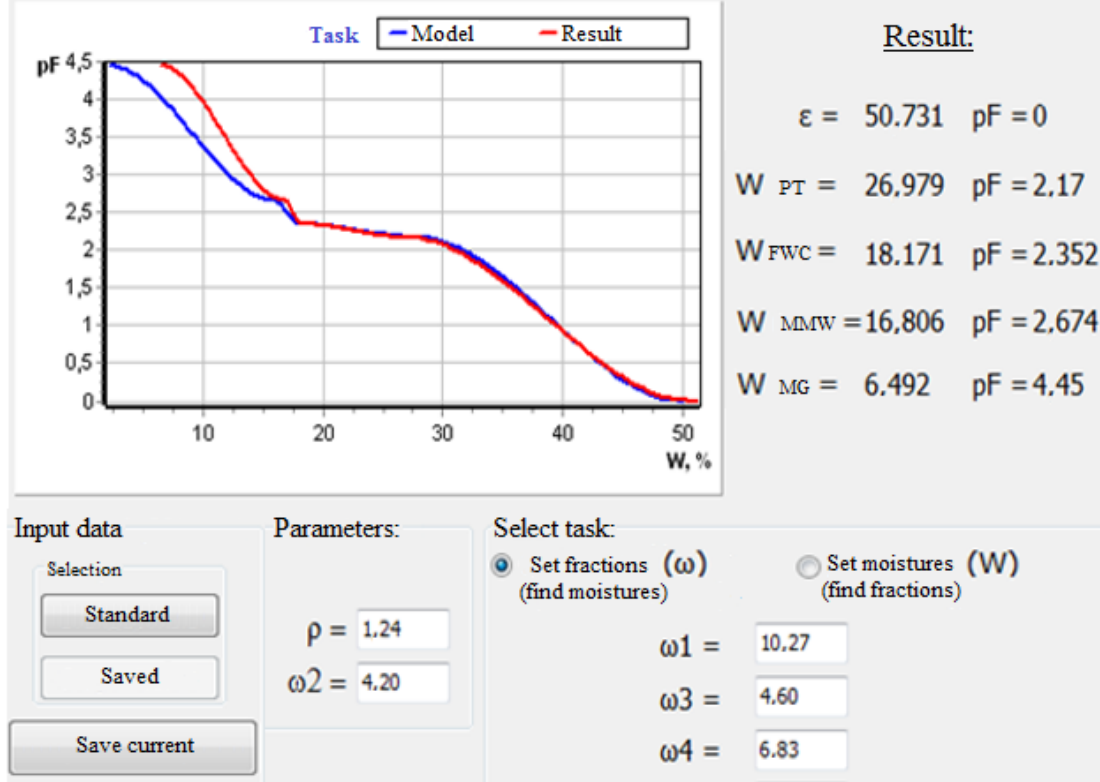
Set moistures (W) (find fractions)

$$
\begin{aligned}
& \omega 1=10.27 \\
& \omega 3=4.60 \\
& \omega 4=6.83 \\
& \omega 5=68.37 \\
& \omega 6=5.73
\end{aligned}
$$

Fig. 3. Main hydrophysical characteristics 1986 section 2.

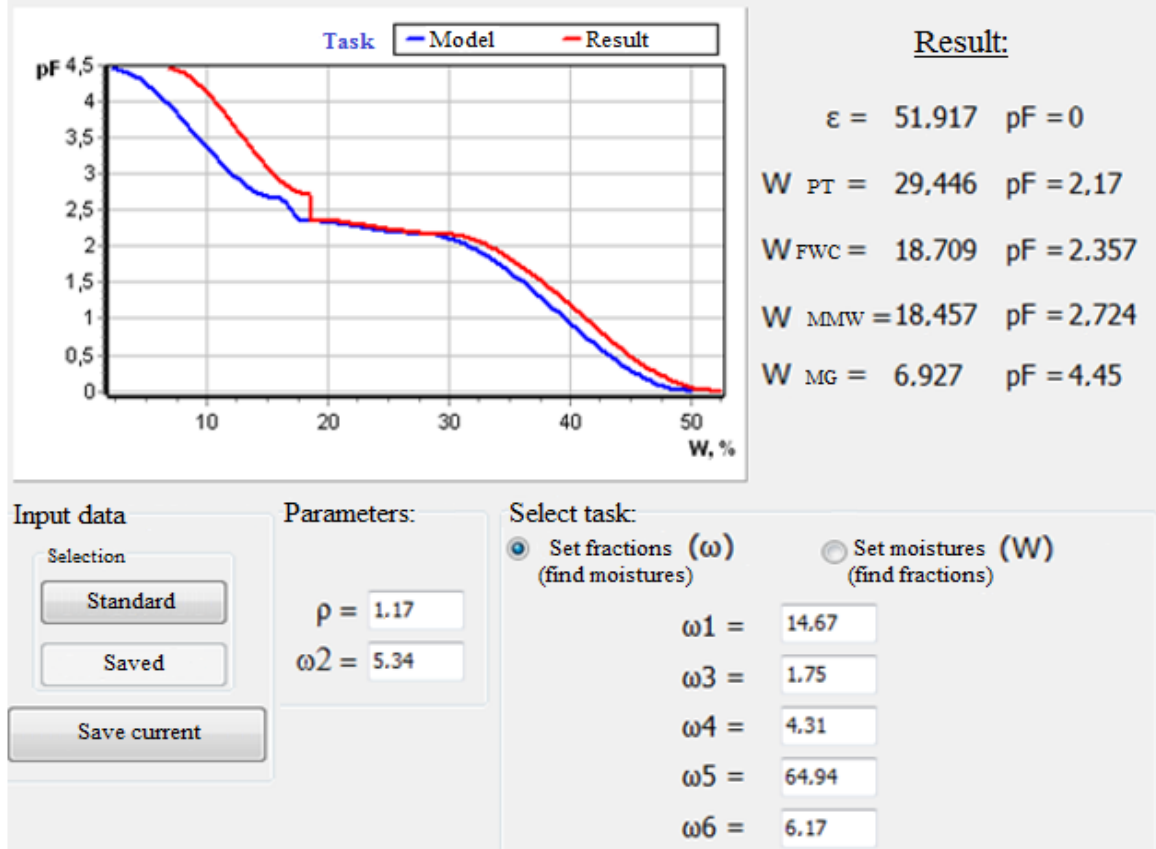

Fig. 4. Main hydrophysical characteristics 2020 section 2. 
According to the figures, it is possible to note changes in the shape of the MHC curve (highlighted in red). These changes are related to the dynamics in the granulometric composition of the studied areas. For 34 years of agricultural use of irrigated soils, there was an increase in the content of fractions of physical clay, silt and fine dust. The content of the fraction of fine sand and coarse dust has decreased. There was a destruction of larger fractions and their transition to smaller fractions. In the layer of 30$40 \mathrm{~cm}$, the accumulation of the silt fraction $(<0.001)$ was noted, which affects the formation of the plough sole. These changes were also reflected in the soil-hydrological constants.

Based on the Voronin crosscuttings [10-13], the values of soil-hydrological constants for 1986 and 2020 were determined (Table No. 1).

Table 1. The main soil-hydrological constants obtained using the "crosscuttings" method according to A.D. Voronin.

\begin{tabular}{|c|c|c|c|c|c|c|c|c|c|c|}
\hline \multirow{2}{*}{$\begin{array}{c}\text { Section } \\
\text { No. }\end{array}$} & \multicolumn{2}{|c|}{ MWC,\% } & \multicolumn{2}{c|}{ FWC,\% } & \multicolumn{2}{c|}{ DCM,\% } & \multicolumn{2}{c|}{ WM,\% } & \multicolumn{2}{c|}{ MG,\% } \\
\cline { 2 - 11 } & 1986 & 2020 & 1986 & 2020 & 1986 & 2020 & 1986 & 2020 & 1986 & 2020 \\
\hline section 1 & 27.38 & 32.65 & 17.88 & 20.65 & 16.81 & 21.30 & 9.55 & 9.69 & 6.37 & 6.46 \\
\hline section 2 & 26.98 & 29.45 & 18.17 & 18.71 & 16.81 & 18.46 & 9.74 & 10.39 & 6.49 & 6.93 \\
\hline
\end{tabular}

The maximum water capacity (MWC) characterizes the largest amount of moisture in the soil that can be contained when filling all the pores with water. In our studies, the maximum water capacity increased slightly from $27.38 \%$ to $32.65 \%$ and from $26.98 \%$ to $29.45 \%$. The field water capacity (FWC) is one of the most important characteristics of the water regime of soils, it shows the greatest amount of water that the soil is able to accumulate and retain for a long time. According to the research results, it was found that the value of the field moisture capacity in the studied area increased slightly from $17.88-18.17 \%$ (data from 1986) to $18.71-20.65 \%$ (data from 2020). The discontinuous capillary moisture (DCM) characterizes the lower limit of the optimal moisture for plants, at which the continuity of the moisture flow through the capillaries and its continuous flow to the roots of plants is disrupted. It was found that this value in the study area increased slightly from $16.81 \%$ when determined in 1986 to $18.46-21.30 \%$ in 2020. Wilting moisture (WM) characterizes the lower limit of moisture available for plants, at these moisture values, plants begin to show signs of wilting. This constant in the studied site increased slightly from $9.55 \%$ to $9.69 \%$ and from $9.74 \%$ to $10.39 \%$. The value of the maximum hygroscopic moisture also increased slightly from $6.37-6.49 \%$ to $6.46-6.93 \%$.

Based on the soil-hydrological constants obtained with the help of MHC, the ranges of gravitational, productive, and easily mobile moisture were calculated (Table 2).

Table 2. Calculated ranges of gravitational, productive and easily mobile soil moisture.

\begin{tabular}{|l|l|l|l|l|l|l|}
\hline \multirow{2}{*}{$\begin{array}{l}\text { Section } \\
\text { No. }\end{array}$} & \multicolumn{2}{l}{$\begin{array}{l}\text { MWC-FWC } \\
\text { (gravitational), }\end{array}$} & $\begin{array}{l}\text { FWC-WM (productive), } \\
\%\end{array}$ & $\begin{array}{l}\text { FWC-DCM } \\
\text { mobile), } \%\end{array}$ \\
\cline { 2 - 7 } & 1986 & 2020 & 1986 & 2020 & 1986 & 2020 \\
\hline section 1 & 9.50 & 12.00 & 8.33 & 10.96 & 1.07 & -0.65 \\
\hline section 2 & 8.81 & 10.74 & 8.43 & 8.32 & 1.36 & -1.17 \\
\hline
\end{tabular}

The range of gravitational moisture corresponds to moisture that fills large pores and moves easily under the influence of gravitational forces. At the maximum content, this form of moisture corresponds to the maximum water capacity (MWC). The difference between total porosity and volume humidity is called aeration porosity or air porosity [14-18]. This is a very important value for the growth and development of plants, the optimal value of which is guaranteed by the structure and aggregate composition. The aeration porosity value is a dynamic value and is related to humidity. The determination of the MHC allowed to estimate the change in the range of gravitational moisture in the 
studied samples, which is essentially its air capacity at FWC. According to the data of 1986 , the range of gravitational moisture was $8.81-9.50 \%$. When determined in 2020 , this range increased to $10.74-12.00 \%$. That is, there is more easily moving moisture in the studied area.

Also, with the help of Voronin crosscuttings, the range of available or productive moisture was determined, indicating the amount of moisture available for plants. The value of this indicator in 2020 in the studied site of the first section increased slightly compared to 1986 from $8.33 \%$ to $10.96 \%$, and in the second section there is a slight decrease in productive moisture from $8.43 \%$ to $8.32 \%$.

The FWC-DCM range characterizes that part of the productive moisture that is easily mobile and easily accessible to plants. In the samples of 1986, this range was $1.07-1.36 \%$. When re-determined in the samples of 2020, this range assumed negative values of $-0.65 \%$ and $-1.17 \%$, respectively, by sections.

\section{Conclusions}

Thus, studies of the hydrophysical parameters of soils and their transformation after 34 years of operation of irrigated areas revealed noticeable transformations of both the shapes of the MHC curves and the values of soil-hydrological constants, and the ranges of soil moisture categories, which is a consequence of an increase in the differentiation of the pore space, changes in the microstructure of the solid phase of the soil.

Based on this, it should be remembered that it is necessary to select an irrigation system (irrigation rate, irrigation method, irrigation timing) to obtain high results, considering technical and economic indicators. At present, with the use of technologies, it has become much easier to do this. We should not forget that for a more accurate description of moisture transfer, complete comprehensive studies are necessary, which include various methods.

\section{References}

1. F.R. Seidelman, Soil reclamation, 448 (Moscow: MSU Publishing House, 2003)

2. R.P. Gupta, P. Aggarval, A.S. Chauhan, Journal of the Indian Society of Soil Science Spatial Variability Analysis of Bulk density as a Guide for Tillage 43(4), 549-557 (1995)

3. J.W. Jones, B.A. Keating, C.H. Porter, Journal Agricultural Systems of the Approaches to modular model development 70, $421-443$ (2001)

4. L. Mueller, G. Shepherd, U. Schindler, Journal Soil and Tillage Research of the Evaluation of soil structure in the framework of an overall soil quality rating 127, 74-84 (2013)

5. A.V. Chelovechkova, I.V. Komissarova, D.I. Eremin, Environmental Management and Tourism Forecasting Water Saturation of Fill Grounds in Urban Infrastructure Conditions by Mathematical Modeling Based on the Main Hydrophysical Characteristic IX 3(27), 485-490 (2018)

6. A.V. Chelovechkova, I.V. Komissarova, D.I. Eremin, IOP Conference Series: Earth and Environmental Science 194, 092004 (2018)

7. A.V. Chelovechkova, Agrarian Bulletin of the 3, 13-18 (2014)

8. A.V. Chelovechkova, E.N. Polyakova, D.I. Dik, IOP Conference Series: Earth and Environmental Science 272, 022155 (2019) 
9. A.V. Chelovechkova, E.N. Polyakova, T.R. Zmyzgova, environment Series Atlantis Highlights in Material Sciences and Technology ISEES, Mathematical methods and computer modeling to predict the formation of the fill grounds in urban 767-770 (2019)

10. A.V. Voronin, Structural and functional hydrophysics of soils, 203 (Moscow: MSU Publishing House, 1984)

11. A.M. Globus, Soil-hydrophysical support of agroecological mathematical models, 427 (Leningrad: Hydrometeoizdat, 1987)

12. I.M. Ryzhova Mathematical modeling of soil processes, 86 (Moscow: MSU Publishing House, 1987)

13. E.V. Shein, I.A. Pachepsky, A.K. Guber, T.I. Chekhov, Soil Science 12, 1479-1486 (1995)

14. E.V. Shein, Soil science, 1, 49-53 (1999)

15. D. Eremin, D. Eremina, Procedia Engineering 165, 788-793 (2018)

16. L. Arya, J.F. Paris, SSSAJ Aphysicoempirical model to predict soil moisture characteristics from particle-size distribution and bulk density data 45, 1023-1030 (1981)

17. J. Bachmann, K.H. Hartge, Z. Pflansenernahr Bodenkd, Estimating soil water characteristics obtained by basic soil data A comparison of indirect methods 109114 (1991)

18. C. Belmans, Jg. Wesseling, R.A. Feddes SWATRE Hydrol 63 Simulation of the water balance of a cropped soil 271-286 (1983)

19. I.M. Ryzhova, Mathematical modeling of soil processes, 86 (Moscow: MSU Publishing House, 1987) 